International Journal of Modern Physics B Vol. 28, No. 23 (2014) 1492004 (1 page)

(C) World Scientific Publishing Company

DOI: 10.1142/S0217979214920040

\title{
Erratum:
}

\section{Nature-like photosynthesis of water and carbon dioxide with femtosecond laser induced self-assembled metal nanostructures}

\author{
[Int. J. Mod. Phys. B, Vol. 23, No. 31 (2009) 5849-5857] \\ Cong Wang, Mengyan Shen*, Haibin Huo, Haizhou Ren, \\ Fadong Yan and Michael Johnson \\ Department of Physics and Applied Physics, and Nanomanufacturing Center, \\ University of Massachusetts, Lowell, One University Avenue, \\ Lowell, MA 01854, USA \\ *Mengyan_Shen@uml.edu
}

Published 8 July 2014

The $10 \%$ efficiency for storing solar energy in products of the plasmonicallycatalyzed artificial synthesis reaction was not accurate and overestimated due to the imprecise weighting of the solid-like hydrocarbons and the errors in calibration of the analytical chemistry equipment with which we quantified the reaction product.

\footnotetext{
*Corresponding author.
} 